\title{
Proinsulin: from hormonal precursor to neuroprotective factor
}

\author{
Enrique J. de la Rosa ${ }^{* \dagger}$ and Flora de Pablo ${ }^{1,2} * t$ \\ 3D Lab (Development, Differentiation and Degeneration), Department of Cellular and Molecular Medicine, Centro de Investigaciones Biológicas, Consejo Superior \\ de Investigaciones Cientificas, Madrid, Spain \\ ${ }^{2}$ The Center for Biomedical Research in Diabetes and Associated Metabolic Disorders (CIBERDEM), Instituto de Salud Carlos III, Ministerio de Ciencia e Innovación, \\ Barcelona, Spain
}

\section{Edited by:}

Isabel Varela-Nieto, Consejo Superior de Investigaciones Científicas, Spain

\section{Reviewed by:}

Iñigo Azcoitia, Universidad

Complutense de Madrid, Spain Julie Ann Chowen, Hospital Infantil

Universitario Niño Jesús, Spain

\section{*Correspondence:}

Enrique J. de la Rosa and Flora de Pablo, Centro de Investigaciones Biológicas, Consejo Superior de Investigaciones Científicas, Ramiro de Maeztu 9, 28040, Madrid, Spain e-mail: ejdelarosa@cib.csic.es; fdepablo@cib.csic.es

${ }^{+}$Senior co-authors
In the last decade, non-canonical functions have been described for several molecules with hormone-like activities in different stages of vertebrate development. Since its purification in the 1960s, proinsulin has been one of the best described hormonal precursors, though it has been overwhelmingly studied in the context of insulin, the mature protein secreted by the pancreas. Beginning with our discovery of the presence and precise regulation of proinsulin mRNA in early neurulation and neurogenesis, we uncovered a role for proinsulin in cell survival in the developing nervous system. We subsequently demonstrated the ability of proinsulin to prevent pathological cell death and delay photoreceptor degeneration in a mouse model of retinitis pigmentosa. In this review, we focus on the evolution of proinsulin/insulin, beginning with insulin-like peptides expressed in mainly the neurosecretory cells of some invertebrates. We summarize findings related to the regulation of proinsulin expression during development and discuss the possible effects of proinsulin in neural cells or tissue, and its potential as a neuroprotective molecule.

Keywords: proinsulin, insulin gene, neural development, neuroprotection, retinitis pigmentosa

\section{EVOLUTION OF INSULIN; GENE LOCI; AND PROTEIN}

Since the discovery of insulin as a metabolically essential pancreatic hormone by Banting and Best in 1921, this protein has been the subject of intensive research. The overwhelming amount of information on insulin structure and function, its receptor, and the consequences of its dysfunction in diabetes mellitus, has overshadowed the importance of proinsulin, the primary product of the insulin gene, and the protein precursor of insulin. The new roles of proinsulin in development described by ours and other groups (reviewed in Hernández-Sánchez et al., 2006) have led to the inclusion of proinsulin as a member, in its own right, of the insulin superfamily of signaling factors, which in humans also includes the insulin-like growth factors (IGFs) -1 and -2 and -7 members of the relaxin-like peptides subfamily (Wilkinson and Bathgate, 2007). This diversity indicates that the evolutionary history of insulin began well before the appearance of the endocrine pancreas.

Proinsulin/insulin, IGFs, and related factors comprise an essential group of proteins in all metazoans, with a broad functional spectrum, including roles in carbohydrate and lipid metabolism, cell and organism growth, cell survival, life span, and reproduction (Nakae et al., 2001; Taguchi and White, 2008). The insulin receptor (IR) is an evolutionarily conserved member of the tyrosine kinase class of cell membrane receptors. A closely related IGF type 1 receptor (IGFR) and an orphan insulin receptor-related receptor (IRR) have been described in mammals (Hernández-Sánchez et al., 2008), as well as an unrelated IGF type 2/Mannose-6phosphate receptor which binds only IGF-2. Intriguingly, despite the antiquity of this metazoan signaling system, a greater number of peptide ligands has been described in invertebrates, in which a single insulin/IGF receptor has been found (up to and including Amphioxus), than in vertebrates. Conversely, vertebrates exhibit a greater diversity of membrane receptors (see later). Though its functional significance remains to be clarified, an extremely well conserved gene synteny is observed in both vertebrates and invertebrates, termed the "tyrosine hydroxylase (th)-insulin cluster." The ancestral insulin gene (INS2) is located between th, or a related invertebrate gene, and an adjacent gene member of the insulin family: igf2 in vertebrates, and multiple insulin-like peptides in invertebrates such as Drosophila melanogaster and Caenorhabditis elegans (Figure 1).

Some of the multiple insulin-related gene products found in lower vertebrates and invertebrates are thought to be related to the ancestral molecule of the vertebrate insulin-IGFs. Since full characterization of these proteins has not been reported for most species, a few may in fact be structurally more similar to the vertebrate proinsulin than to the mature pancreatic insulin. In this review, insulin gene will be used to refer to the genomic locus and sequence, as this is the term used in gene banks. When discussing RNA data, we will use the term proinsulin mRNA, and for protein data we will specify whether we refer to mature insulin or another evolutionary (insulin-like) or developmental (proinsulin) precursor.

The D. melanogaster genome contains seven insulin-like genes (dilp1-7) that are expressed in a stage-, tissue-, or cell-specific manner (Brogiolo et al., 2001). Of these, dilp2 is the most closely related to human insulin (35\% sequence identity), while dilp6 and 


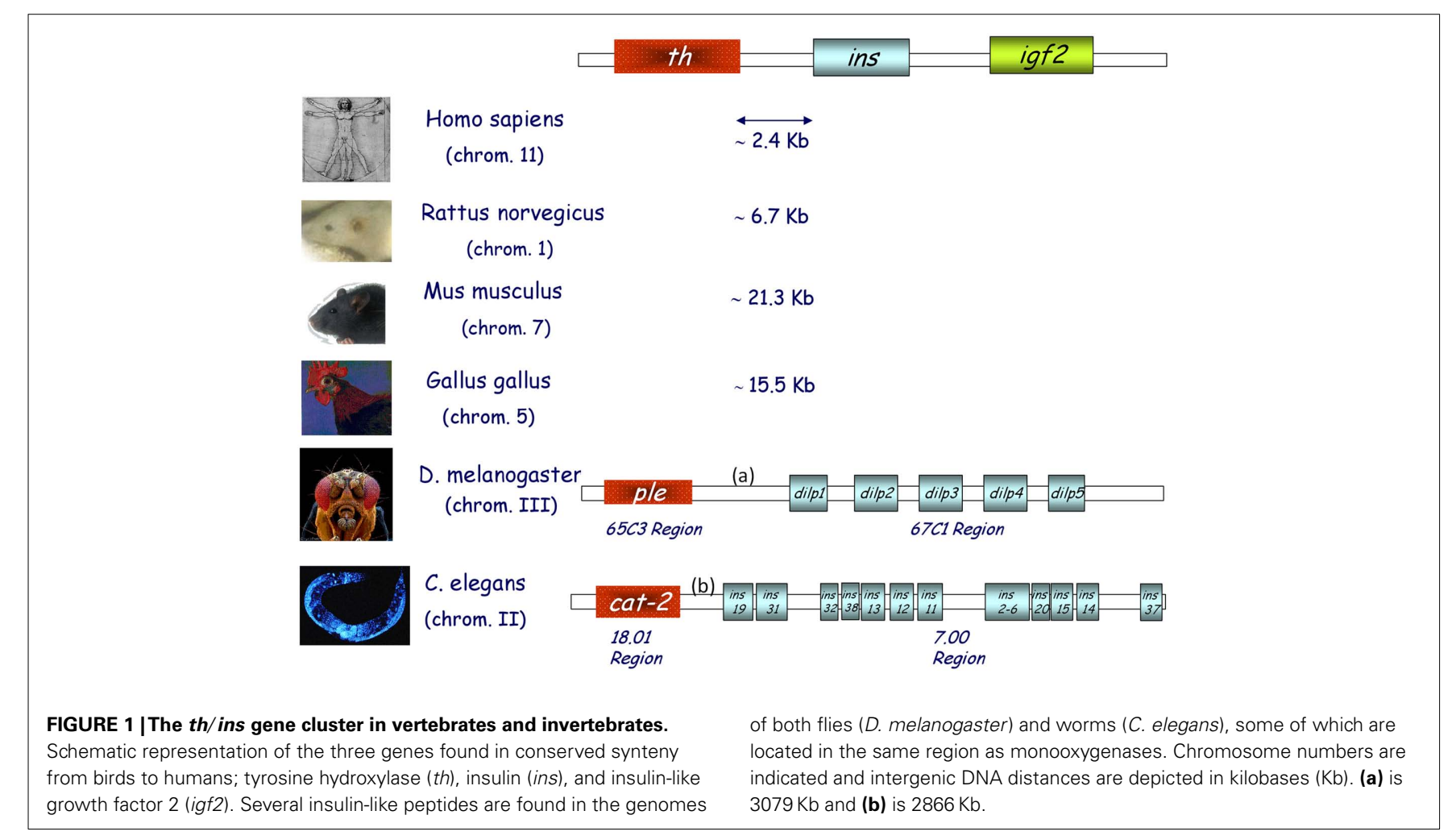

dilp7 represent the most distant relatives. Four of these genes, dilp 1,2,3, and 5, are coexpressed in small clusters of cells in larval brain neurons (Rulifson et al., 2002). As ablation of these cells causes developmental delays, growth retardation, and elevated carbohydrate levels in larval hemolymph, a functional analogy to vertebrate pancreatic $\beta$ cells has been proposed (Rulifson et al., 2002). Dilp6 is expressed in the larval body fat and controlled by the steroid hormone ecdysone during metamorphosis upon termination of feeding to relay the growth signal, and thus is functionally more similar to vertebrate IGFs (Slaidina et al., 2009). Dilp7 is found in abdominal ganglia and may play a reproductive role. Dilp $1-5$ bind to the D. melanogaster single insulin/IGF receptor (33\% sequence identity with the vertebrate homologs, Fernández et al., 1995). Recently, the crystal structure of two DILP5 variants that differ by three amino acids at the N-terminal end of the A-chain was described (Sajid et al., 2011). Both variants share the basic fold of the insulin peptide family but exhibit an unusual dimeric structure. Insulin producing cells in the Drosophila brain express one of the four known serotonin receptor signaling types (5-HT1A) and the metabotropic receptor $G A B A_{B}$. The ionotropic $\mathrm{GABA}_{\mathrm{A}}$ receptor subunit RDL is not expressed by these cells. Increases in DILP expression resulting from interference with $\mathrm{GABA}_{B}$ or 5-HT1A receptor signaling shortens life span, decreases stress resistance and alters carbohydrate, and lipid metabolism in response to stress (Nässel and Winther, 2010).

The most important role attributed to the insulin/IR pathway in C. elegans relates to longevity. Remarkably, the only insulin/IGF receptor ortholog expressed by this short-lived worm, DAF-2, was implicated in the function and evolutionary conservation of the first life-span pathway to be discovered (for review see Kenyon,
2010, 2011). However, much less is known about the function of specific peptides of this family. The C. elegans genome encodes 40 putative insulin-like peptides, many of which are expressed at low levels in whole worms. Recently, the powerful nCounter platform was used to quantify insulin-like mRNA expression for all of these peptides, revealing a variety of distinct developmental patterns of expression and suggesting a considerable complexity of regulation and specificity of function (Baugh et al., 2011). Many of the 40 C. elegans insulin-like peptides are found in overlapping subsets of sensory neurons and/or interneurons, including the sensory neurons that regulate dauer (a diapause stage induced in harsh environmental conditions) entry or exit. Specifically, ins1 mediates dauer arrest under harsh environments, while daf-28 and ins-6 ensure reproductive growth under favorable conditions. daf-28 and ins-6 also play key roles in inhibiting dauer entry and promoting dauer exit, respectively (Cornils et al., 2011). Taken together, these findings indicate that insulin-like peptides have been involved in the physiology of the nervous system since early in evolution, a role that is highly conserved in higher vertebrates.

\section{PROINSULIN TRANSCRIPTS IN DEVELOPMENT AND PROINSULIN STRUCTURE}

Proinsulin was isolated in the 1960s by the group of Steiner et al. (1990), and was initially considered a low metabolic activity protein precursor of insulin. Based on our studies of insulin expression early in development, particularly in the embryonic chick nervous system, we discovered proinsulin to be the final protein form secreted by extrapancreatic tissues (De Pablo et al., 1990; Hernández-Sánchez et al., 1995, 2002). While the pancreatic regulation of proinsulin mRNA expression was initially considered 
highly tissue-specific (Steiner et al., 1990), our discovery of a series of proinsulin transcripts in the chick embryo during prepancreatic development challenged the view of the pancreas as an exclusive source of proinsulin (Figure 2). The ancestral insulin gene (only one gene is found in most of the vertebrate genomes including chick, whereas mouse, rat, and Xenopus express two non-allelic genes) contains three exons. The open reading frame spans most of exon 2 and all of exon 3, coding for the B, C, and A domains of proinsulin (Figure 2). It is plausible that the control of cell survival in embryos requires the subtle regulation of proinsulin expression in a different manner to that characteristic of the $\beta$ cells of the vertebrate pancreas. We characterized a specific embryonic form of proinsulin mRNA (pro1B) with a 32 nucleotide extension in the $5^{\prime}$ UTR which shared its coding region with the pancreatic transcript (Pro1A). However, the embryonic transcript exhibits much lower translational activity due to the presence of two extra AUGs in the 32-nucleotide 5'-extension (Figure 3; Hernández-Sánchez et al., 2003). We subsequently identified an additional embryonic proinsulin mRNA generated by the retention of the first intron in the $5^{\prime}$ UTR. This large, structured 5' UTR almost blocks proinsulin translation, whereas mRNA transport and cytoplasmic stability are unaffected (Mansilla et al., 2005). The relative proportion of these transcripts varied in developing organs (see later and Figure 3), indicating a significant level of post-transcriptional control of the insulin gene during vertebrate development.
Detailed screening of embryonic proinsulin transcripts led us to another unexpected finding: both chick and quail embryos express chimeric mRNAs containing exons from both th and insulin genes, transcribed in a regulated manner (Figure 2; Hernández-Sánchez et al., 2006). The TH-INS1 and TH-INS2 chimeras differ in their insulin gene content, and encode two novel isoforms of the $\mathrm{TH}$ protein with markedly reduced functionality, as compared with canonical TH. In addition, TH-INS1 chimeric mRNA generates a small amount of proinsulin/insulin. At least TH-INS1 is found in the neurulating embryo and in the substantia nigra of the embryonic day (E) 18 chick embryo, though its function remains unknown. insulin-igf2 chimeric mRNAs have also been described in the human fetal eye and pancreas, which do not produce proinsulin (Monk et al., 2006).

The basic fold shared by known members of the insulin superfamily consists of a B domain containing a single $\alpha$-helix that lies across the two $\alpha$-helices of the A domain (Murray-Rust et al., 1992). Two canonical disulfide bridges connect the Aand B-chains, while the A-chain contains an intrachain disulfide bridge. The $\mathrm{C}$-peptide is cleaved out in mature pancreatic insulin (Figure 2B). As proinsulin is refractory to crystallization, heteronuclear NMR spectroscopy has been employed to characterize a monomeric analog. It has been proposed that flexibility at each $\mathrm{C}$-domain junction facilitates prohormone processing by convertases (Figure 2C; Yang et al., 2010). We demonstrated that
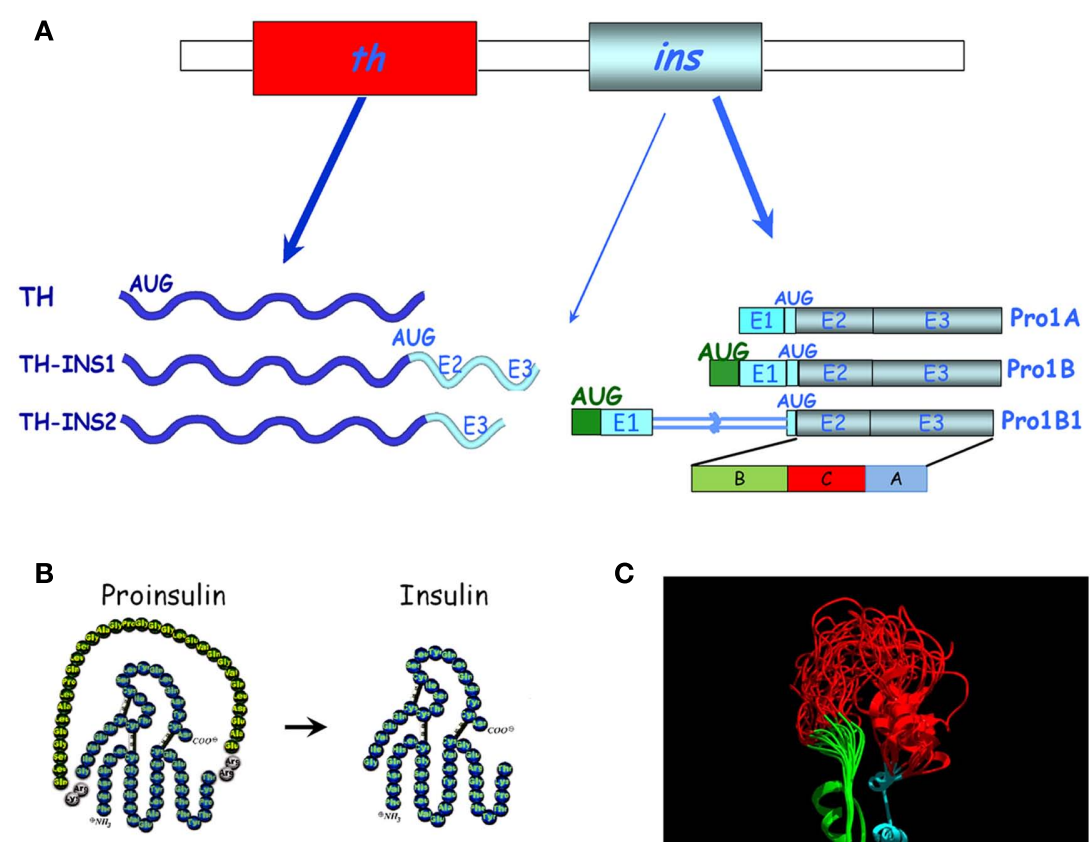

C

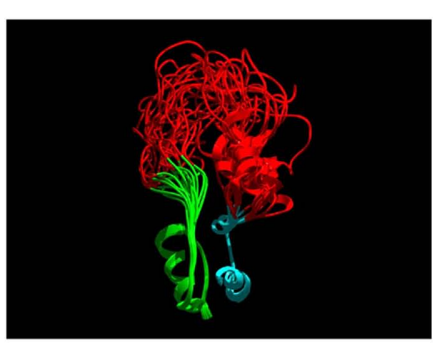

FIGURE 2 | Diversity of proinsulin transcripts and chimeric transcripts in chick embryos. (A) The canonical th and the pancreatic proinsulin mRNAs (Pro1A) are shown in the top panel. Below are alternative transcripts found in embryos, either chimeric mRNAs (TH-INS1, TH-INS2) or proinsulin mRNAs with an extended 5' UTR (Pro1B and Pro1B1). The translation initiation codon (AUG) and additional AUGs are indicated (modified from Hernández-Sánchez et al., 2006). The (B,C,A) protein domains of proinsulin are marked. E, exon.

(B) Schematic representation of the amino acid composition of proinsulin and insulin after C-peptide cleavage. (C) Structural model of proinsulin. The ribbon rendered backbone highlights the conformational variability of the NMR-resolved human-proinsulin, based on Yang et al. (2010). The B-chain (green), A-chain (cyan), and the C-peptide (red) are depicted before proinsulin processing. The model (courtesy of Mario García-de Lacoba, CIB, CSIC) demonstrates the great conformational flexibility of the C-peptide. 


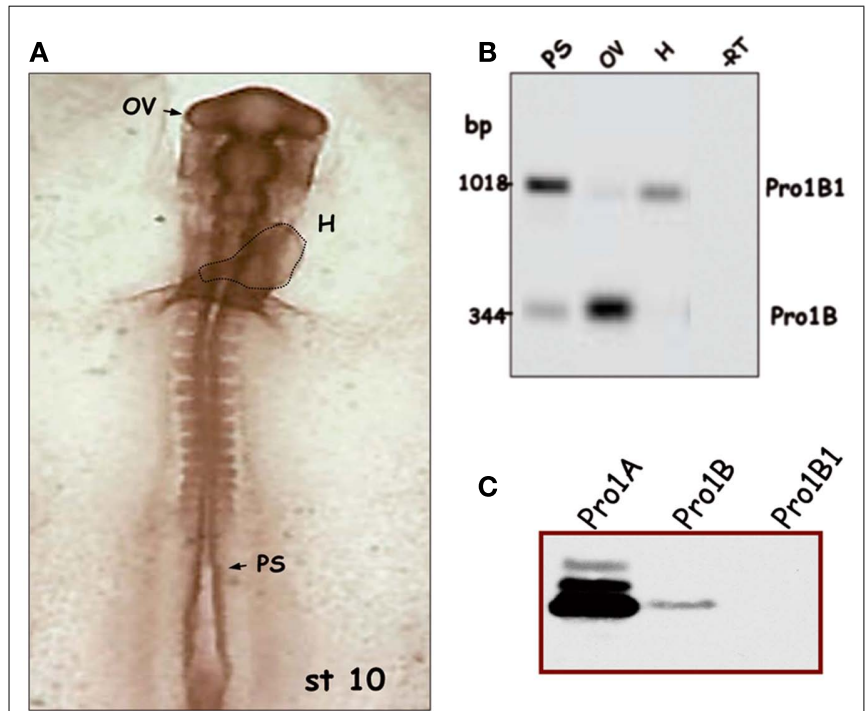

FIGURE 3 | Regulated splicing pattern of embryonic proinsulin mRNA. (A) Stage 10 chick embryo (approximately $36 \mathrm{~h}$ of development) with the dotted line indicating the embryonic heart $(H)$; the presomitic region (PS), and optic vesicle (OV) are depicted. (B) Proinsulin reverse transcription-PCR followed by Southern blot of RNA from different regions of stage 10 embryos. Intron 1 is retained in the Pro1B1 transcript, but spliced out in Pro1B. The latter form predominates in the OV (largely neuroepithelium at this stage) and is relatively less abundant in other embryonic regions. (C) Proinsulin expression in NIH3T3 cells transfected with the indicated construct. Modified from Mansilla et al. (2005).

proinsulin remains unprocessed in the neurulating chick embryo and the neuroretina due to the lack of expression of at least one of the proinsulin convertases, PC2 (Alarcón et al., 1998; HernándezSánchez et al., 2002). Neural proinsulin is likely to be secreted by a constitutive secretory pathway. In cultured neuroretina, rapid secretion of proinsulin into the medium occurred within a few hours, even in the absence of secretagogues (Hernández-Sánchez et al., 1995).

\section{REGULATION OF PROINSULIN EXPRESSION IN EARLY DEVELOPMENT}

Prepancreatic and extrapancreatic proinsulin mRNA expression is much lower than that observed in the mature vertebrate pancreas (Serrano et al., 1989; Pérez-Villamil et al., 1994), but can be clearly detected in the chick embryo during gastrulation and neurulation (Morales et al., 1997) and in the embryonic retinal neuroepithelium at E3 (Díaz et al., 1999). Proinsulin protein, as detected with anti-C peptide antibody, is present in discrete cells located in the three embryonic layers of the chick embryo, though mainly in the neuroepithelium, prior to IGF-1 expression (HernándezSánchez et al., 2002). In contrast with the pancreatic transcripts, embryonic proinsulin mRNA levels are not regulated by glucose (Pérez-Villamil et al., 1994), suggesting that alternative mechanisms of regulation are operative in early embryos. As described above, an alternative transcription start site exists in neurulating chick embryos (generating transcript Pro1B), and retention of intron 1 occurs in another embryonic form of proinsulin embryonic mRNA (Pro1B1). These features impact on the respective translational levels (Figure 3C; Hernández-Sánchez et al., 2003; Mansilla et al., 2005). An example of the modulation of the proinsulin splicing pattern in chick embryos undergoing neurulation and early organogenesis is shown in Figure 3B. Proinsulin intron 1 was efficiently spliced out in the optic vesicle, but retained in the heart tube and presomitic region. The developing eye, therefore, displays a translationally more active form of proinsulin mRNA than other embryo regions, at a time when the IR is expressed and active (Girbau et al., 1989). The role of proinsulin during early stages of neural development is discussed below.

\section{DISTINCT ACTIONS OF PROINSULIN IN THE DEVELOPING NERVOUS SYSTEM}

The study of a possible physiological function of proinsulin in vertebrates has been hindered by both the essential metabolic role of its processed product, the insulin hormone, and the classification of IGF-1 and IGF-2 as the "genuine growth factors" of the family. However, the phylogenic and ontogenic expression data presented above support a role for proinsulin as a growth factor in its own right.

The roles of IGF-1 in nervous system have been extensively characterized and include, among others, neuroprotection during development and in the adult brain (D'Ercole and Ye, 2008; TorresAleman, 2010). Moreover, the physiological actions of insulin in the nervous system, previously considered an insulin-insensitive tissue, are increasingly recognized, particularly at the level of synapse development and plasticity (Abbott et al., 1999; Chiu and Cline, 2010). However, recent studies have revealed that insulin and IGF-1 are not the only members of this family of physiological factors active in early developmental stages.

A key aspect of putative proinsulin action involves receptor availability. The classical composition of this tyrosine kinase receptor consists of a homodimeric $\alpha_{2} \beta_{2}$ entity resulting from the post-translational cleavage of a single protein product into two subunits, $\alpha$ and $\beta$. Both subunits are then covalently re-bound by a disulfide bond to form a monomer, and two monomers in turn covalently bound by two disulfide bonds between the $\alpha$ subunits form a homodimeric receptor. An extensive review of the receptor gene and protein structure has been recently published (Belfiore et al., 2009). Classical IRs display a reduced affinity for proinsulin, about one order of magnitude lower than that of insulin. Similarly, classical IGFRs cannot bind physiological concentrations of proinsulin (De Pablo et al., 1990). However, in the embryonic chick neuroretina at early proliferative stages, proinsulin-mediated signaling appears to occur through an atypical, promiscuous receptor, which is also activated by insulin and IGF-1 (García-de Lacoba et al., 1999). It should be noted that, at the ligand level, proinsulin appears to be the main factor present at this developmental stage. Without distinguishing between proinsulin and insulin, insulinlike immunoreactivity in the vitreous humor filling the chick embryonic eye is 100 times higher than IGF-1-like immunoreactivity (Hernández-Sánchez et al., 1995). Moreover, when immunoblot analysis was performed, the only identified product present in the neurulating chick embryo and embryonic retina was proinsulin (Alarcón et al., 1998; Hernández-Sánchez et al., 2002).

It is possible that proinsulin binds to a hybrid receptor in the embryonic chick retina, composed of an $\alpha \beta$ monomer of the IR 
and a $\alpha \beta$ monomer of the IGFR. While such receptors are found in the early embryonic retina, when proinsulin is active, their presence decreases as the retina matures. In parallel, homodimeric IRs become more abundant, and proinsulin less active, with retinal maturation (García-de Lacoba et al., 1999). The situation is even more complex in mammals, where the IR contains an additional, 11 th exon (called IR-B), which is spliced out in fetal, and nonmetabolic tissues. IR lacking exon 11 (IR-A form) also display a promiscuous binding capacity, particularly for IGF-2 (Belfiore et al., 2009; Chiu and Cline, 2010), though its affinity for proinsulin remains to be determined. Furthermore, the presence of three hybrid receptors, IR-A/IR-B, IR-A/IGFR, and IR-B/IGFR is suspected in different tissues, particularly in the nervous system and in transformed cells, suggesting a complex interplay between possible ligands and cellular effects (Belfiore et al., 2009).

Proinsulin promotes cell proliferation, differentiation, and survival in the embryonic chick and mouse nervous system (Hernández-Sánchez et al., 1995; Díaz et al., 1999, 2000; Valenciano et al., 2006). Its primary role, however, appears to be the regulation of cell survival during early neural development under normal conditions, resulting in increased numbers of proliferating neuroepithelial cells or neurons. Conversely, blocking antibodies targeting the IR induce apoptosis in the early chick retina, decreasing neuronal numbers (Figure 4; Díaz et al., 2000). A similar apoptotic

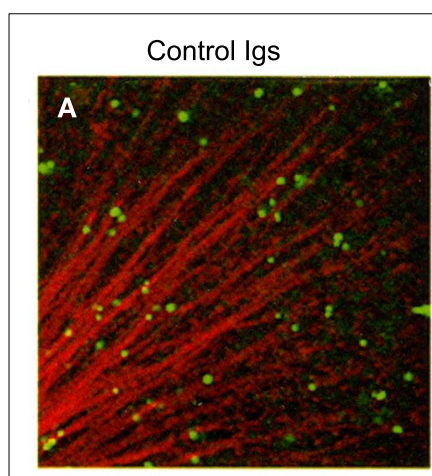

\section{Anti-Insulin Receptor Igs}
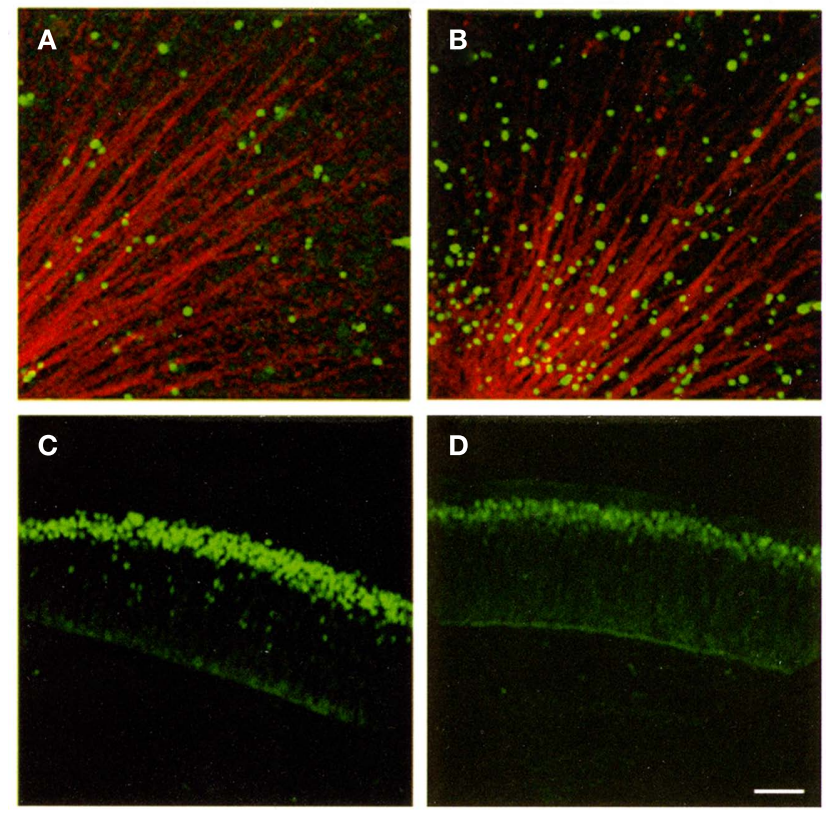

FIGURE 4 | Interference with the insulin receptor increases cell death and decreases the number of retinal ganglion cell neurons in the embryonic chick retina. E2 chick embryos were treated in vivo with control or anti-insulin receptor antibodies. TUNEL-positive cells [in green $(\mathbf{A}, \mathbf{B})$ ] were visualized in E4 flat-mount retinas. Optic fibers were labeled by G4/Ng-CAM immunostaining (in red). Retinal ganglion cells were visualized by Islet 1/2 immunostaining [in green (C,D)] in E6 retinal sections. Reproduced from Díaz et al. (2000) with permission; C2000, Company of Biologists. Scale bar $=50 \mu \mathrm{m}$. effect is observed when antisense oligonucleotides targeting the IR are used to interfere with proinsulin signaling (HernándezSánchez et al., 2002). Treatment with exogenous proinsulin in ovo results in a decrease in naturally occurring apoptosis and leads to developmental abnormalities in the neural tube and optic vesicles, indicating that controlled regulation of proinsulin expression and function is crucial for proper neural development (Hernández-Sánchez et al., 2003).

\section{OTHER PHYSIOLOGICAL AND PATHOLOGICAL NEURAL PROCESSES DEPENDENT UPON IR-SIGNALING}

As stated earlier, growing evidence has described several insulin actions in tissues previously considered insulin-insensitive (Ogg et al., 2005). Given the lack of studies of proinsulin expression and binding capacity, together with promiscuity of the receptors involved, it is plausible that some of the actions described for insulin and IGF-1 may be in fact mediated by either physiological or reactive to disease proinsulin activity. One such example is the effect of proinsulin in attenuating pathological cell death in the retina in a murine model of retinal dystrophy. The $r d 10$ mouse is a model of human retinitis pigmentosa. One-month-old $r d 10$ mice are almost blind due to a degenerative process that involves apoptosis of the photoreceptor cells in the retina (Barhoum et al., 2008). Transgenic expression of human proinsulin delays vision loss, a phenomenon that correlates with decreased cell death and the preservation of the photoreceptor layer with more rods and cones, and better synaptic connections (Figure 5; Corrochano
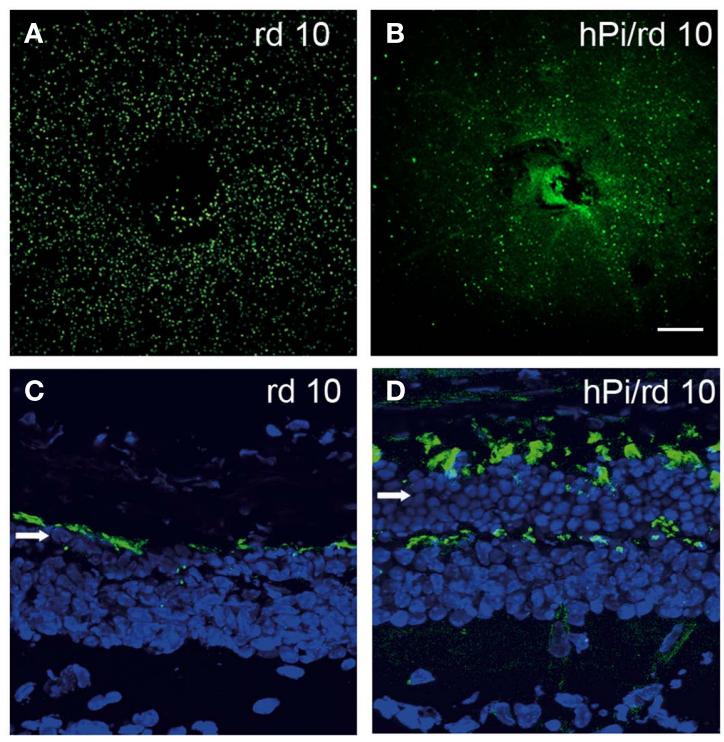

FIGURE 5 | Photoreceptor cell death is delayed and the photoreceptor layer is preserved in rd10 mice expressing proinsulin. Cell death was visualized by TUNEL in P25 flat-mount retinas of $r d 10$ and $\mathrm{hPi} / \mathrm{rd} 10$ transgenic mice [in green $(\mathbf{A}, \mathbf{B})$ ]. Retinal cytoarchitecture was visualized with Alexa 488-peanut agglutinin [green-labeled cones (C,D)] and DAPI staining [blue (C,D); arrow indicates photoreceptor rows] in P32 retinal sections. Reproduced from Corrochano et al. (2008) with permission; C2008, The Association for Research in Vision and Ophthalmology. Scale bars $=200 \mu \mathrm{m}$ in $(\mathbf{A}, \mathbf{B})$ and $25 \mu \mathrm{m}$ in $\mathbf{( C , D )}$. 
et al., 2008). Clearly, proinsulin can activate cellular processes in the dystrophic retina, though the receptors involved remain to be identified.

Physiological and pathological aging, as well as life span, are other processes potentially modulated by the activity of proinsulin (see for a review Taguchi and White, 2008). Although initially related to IGF-1 signaling, several observations have implicated insulin sensitivity in longevity, while insulin resistance appears to be a feature of neurodegenerative disorders, including Alzheimer's disease, Parkinson's disease, and Lewy body dementia (Schubert et al., 2004; Messier and Teutenberg, 2005; Steen et al., 2005; Zhao et al., 2008; Tong et al., 2009). Furthermore, synapse formation and maintenance mediated by IR signaling, particularly via the PI3K pathway, may contribute to brain function in both normal and physiological conditions in invertebrates and vertebrates (MartínPeña et al., 2006; Arendt et al., 2010; Chiu and Cline, 2010). While the nature of the proinsulin receptor involved and the levels of local proinsulin synthesis remain undetermined, it should be noted that PI3K inhibition abolishes the pro-survival effects of proinsulin in the developing retina (Valenciano et al., 2006).

\section{PERSPECTIVES FOR FUTURE STUDIES AND USES OF PROINSULIN}

The role of proinsulin, beyond its prohormone function, as a genuine cell survival or tissue growth factor has remained overlooked for half a century. The observations reviewed here encourage future studies to characterize proinsulin expression at the pro-

\section{REFERENCES}

Abbott, M. A., Wells, D. G., and Fallon, J. R. (1999). The insulin receptor tyrosine kinase substrate p58/53 and the insulin receptor are components of CNS synapses. J. Neurosci. 19, 7300-7308.

Alarcón, C., Serna, J., Pérez-Villamil, B., and de Pablo, F. (1998). Synthesis and differentially regulated processing of proinsulin in developing chick pancreas, liver and neuroretina. FEBS Lett. 436, 361-366.

Arendt, K. L., Royo, M., FernándezMonreal, M., Knafo, S., Petrok, C. N., Martens, J. R., and Esteban, J. A. (2010). PIP3 controls synaptic function by maintaining AMPA receptor clustering at the postsynaptic membrane. Nat. Neurosci. 13, 36-44.

Barhoum, R., Martínez-Navarrete, G., Corrochano, S., Germain, F., Fernández-Sánchez, L., de la Rosa, E. J., de la Villa, P., and Cuenca, N. (2008). Functional and structural modifications during retinal degeneration in the rd10 mouse. Neuroscience 155, 698-713.

Baugh, L. R., Kurhanewicz, N., and Sternberg, P. W. (2011). Sensitive and precise quantification of insulin-like mRNA expression in Caenorhabditis elegans. PLoS ONE 6, e18086. doi: 10.1371/journal.pone.0018086
Belfiore, A., Frasca, F., Pandini, G., Insulin receptor isoforms and insulin receptor/insulin-like growth factor receptor hybrids in physiology and disease. Endocr. Rev. 30, 586-623.

Brogiolo, W., Stocker, H., Ikeya, T., Rintelen, F., Fernández, R., and Hafen, E. (2001). An evolutionarily conserved function of the Drosophila insulin receptor and insulin-like peptides in growth control. Curr. Biol. 11, 213-221.

Chiu, S. L., and Cline, H. T. (2010). Insulin receptor signaling in the development of neuronal structure and function. Neural Dev. 15, 5-7.

Cornils, A., Gloeck, M., Chen, Z., Zhang, Y., and Alcedo, J. (2011). Specific insulin-like peptides encode sensory information to regulate distinct developmental processes. Development 138, 1183-1193.

Corrochano, S., Barhoum, R., Boya, P., Arroba, A. I., Rodríguez-Muela, N., Gómez-Vicente, V., Bosch, F., de Pablo, F., de la Villa, P., and de la Rosa, E. J. (2008). Attenuation of vision loss and delay in apoptosis of photoreceptors induced by proinsulin in a mouse model of retinitis pigmentosa. Invest. Ophthalmol. Vis. Sci. 49, 4188-4194.

De Pablo, F., Scott, L. A., and Roth, J. (1990). Insulin and insulin-like Sciacca, L., and Vigneri, R. (2009).

tein level in the developing and adult nervous systems, not only under physiological conditions but also during aging and pathological processes. Particularly, the receptor entities able to bind proinsulin in mammals need to be identified, as a requisite to fully elucidate the physiological relevance of proinsulin, as well as its potential pharmacological use in insulin-resistance conditions or diseases with abnormally increased cell death. The dramatic impact of diabetes and neurodegenerative disorders on our society further highlights the need for new therapeutic strategies that may relay on various factors of the insulin family, to treat these conditions. There are, to our knowledge, no clinical trials presently underway with proinsulin. Indeed, preclinical studies in animal models of retinitis pigmentosa with proinsulin treatment, commented here, are the initial step toward future therapeutical developments.

\section{ACKNOWLEDGMENTS}

We wish to thank Drs. Catalina Hernández-Sánchez and Teresa Suárez for comments on the manuscript and their many contributions over the years to the studies in our laboratory, Dr. Mario García-de Lacoba for the proinsulin structure modeling, Ms. Ana M. Robles for help with the edition of figures and the Ministry of Science, Technology, and Innovation (MICINN) for their funding (SAF2010-21879 to Enrique J. de la Rosa and BFU 2010-15868 to Flora de Pablo). CIBERDEM (CIBER de Diabetes y Enfermedades Metabólicas Asociadas) is a initiative of the Instituto de Salud Carlos III-MICINN.

growth factor I in early development: peptides, receptors and biological events. Endocr. Rev. 11, 558-577.

D'Ercole, A. J., and Ye, P. (2008). Minireview: expanding the mind: insulin-like growth factor I and brain development. Endocrinology 149, 5958-5962.

Díaz, B., Pimentel, B., de Pablo, F., and de la Rosa, E. J. (1999). Apoptotic cell death of proliferating neuroepithelial cells in the embryonic retina is prevented by insulin. Eur. J. Neurosci. 11, 1624-1632.

Díaz, B., Serna, J., de Pablo, F., and de la Rosa, E. J. (2000). In vivo regulation of cell death by embryonic (pro)insulin and the insulin receptor during early retinal neurogenesis. Development 127, 1641-1649.

Fernández, R., Tabarini, D, Azpiazu, N., Frasch, M., and Schlessinger, J. (1995). The Drosophila insulin receptor homolog: a gene essential for embryonic development encodes two receptor isoforms with different signaling potential. EMBO J. 14, 3373-3384.

García-de Lacoba, M., Alarcón, C., de la Rosa, E. J., and de Pablo, F. (1999). Insulin/insulin-like growth factor-I hybrid receptors with high affinity for insulin are developmentally regulated during neurogenesis. Endocrinology 140, 233-243.
Girbau, M., Bassas, L., Alemany, J., and de Pablo, F. (1989). In situ autoradiography and ligand-dependent tyrosine kinase activity reveal insulin receptors and insulin-like growth factor I receptors in prepancreatic chicken embryos. Proc. Natl. Acad. Sci. U.S.A. 86, 5868-5872.

Hernández-Sánchez, C., LópezCarranza, A., Alarcón, C., de la Rosa, E. J., and de Pablo, F. (1995). Autocrine/paracrine role of insulin-related growth factors in neurogenesis: local expression and effects on cell proliferation and differentiation in retina. Proc. Natl. Acad. Sci. U.S.A. 92, 9834-9838.

Hernández-Sánchez, C., Mansilla, A., de la Rosa, E. J., and de Pablo, F. (2006). Proinsulin in development: new roles for an ancient prohormone. Diabetologia 49, 1142-1150.

Hernández-Sánchez, C., Mansilla, A., de la Rosa, E. J., Pollerberg, G. E., Martínez-Salas, E., and de Pablo, F. (2003). Upstream AUGs in embryonic proinsulin mRNA control its low translation level. EMBO J. 22, 5582-5592.

Hernández-Sánchez, C., Mansilla, A., de Pablo, F., and Zardoya, R. (2008). Evolution of the insulin receptor family and receptor isoform expression in vertebrates. Mol. Biol. Evol. 25, 1043-1053. 
Hernández-Sánchez, C., Rubio, E., Serna, J., de la Rosa, E. J., and de Pablo, F. (2002). Unprocessed proinsulin promotes cell survival during neurulation in the chick embryo. Diabetes 51, 770-777.

Kenyon, C. (2010). The genetics of ageing. Nature 464, 504-512.

Kenyon, C. (2011). The first longlived mutants: discovery of the insulin/IGF-1 pathway for ageing. Philos. Trans. R. Soc. Lond. B Biol. Sci. 366, 9-16.

Mansilla, A, López-Sánchez, C., de la Rosa, E. J., García-Martínez, V., Martínez-Salas, E., de Pablo, F., and Hernández-Sánchez, C. (2005). Developmental regulation of a proinsulin messenger RNA generated by intron retention. EMBO Rep. 6, 1182-1187.

Martín-Peña, A., Acebes, A., Rodríguez, J. R., Sorribes, A., de Polavieja, G. G., Fernández-Fúnez, P., and Ferrús, A. (2006). Age-independent synaptogenesis by phosphoinositide 3 kinase. J. Neurosci. 26, 10199-10208.

Messier, C., and Teutenberg, K. (2005). The role of insulin, insulin growth factor, and insulindegrading enzyme in brain aging and Alzheimer's disease. Neural Plast. 12, 311-328.

Monk, D., Sanches, R., Arnaud, P., Apostolidou, S., Hills, F. A., Abu-Amero, S., Murrell, A., Friess, H., Reik, W., Stanier, P., Constância, M., and Moore, G. E. (2006). Imprinting of IGF2 P0 transcript and novel alternatively spliced INS-IGF2 isoforms show differences between mouse and human. Hum. Mol. Genet. 15, 1259-1269.

Morales, A. V., Serna, J., Alarcón, C., de la Rosa, E. J., and de Pablo, F. (1997). Role of prepancreatic (pro)insulin and the insulin receptor in prevention of embryonic apoptosis. Endocrinology 138, 3967-3975.

Murray-Rust, J., McLeod, A. N., Blundell, T. L., and Wood, S. P. (1992). Structure and evolution of insulins: implications for receptor binding. Bioessays 14, 325-331.

Nakae, J., Kido, Y., and Accili, D. (2001). Distinct and overlapping functions of insulin and IGF-I receptors. Endocr. Rev. 22, 818-835.

Nässel, D. R., and Winther, A. M. (2010). Drosophila neuropeptides in regulation of physiology and behavior. Prog. Neurobiol. 92, 42-104.

Ogg, S., Paradis, S., Gottlieb, S., Patterson, G. I., Lee, L., Tissenbaum, H. A., Ruvkun, G., Plum, L., Schubert, M., and Brüning, J. C. (2005). The role of insulin receptor signaling in the brain. Trends Endocrinol. Metab. 16, 59-65.

Pérez-Villamil, B., de la Rosa, E. J., Morales, A. V., and de Pablo, F. (1994). Developmentally regulated expression of the preproinsulin gene in the chicken embryo during gastrulation and neurulation. Endocrinology 135, 2342-2350.

Rulifson, E. J., Kim, S. K., and Nusse, R. (2002). Ablation of insulinproducing neurons in flies: growth and diabetic phenotypes. Science 296, 1118-1120.

Sajid, W., Kulahin, N., Schluckebier, G., Ribel, U., Henderson, H. R., Tatar, M., Hansen, B. F., Svendsen, A. M., Kiselyov, V. V., Nørgaard, P., Wahlund, P. O., Brandt, J., Kohanski, R. A., Andersen, A. S., and de Meyts, P. (2011). Structural and biological properties of the Drosophila insulin-like peptide 5 show evolutionary conservation. J. Biol. Chem. 286. 661-673.

Schubert, M., Gautam, D., Surjo, D., Ueki, K., Baudler, S., Schubert, D., Kondo, T., Alber, J., Galldiks, N.,
Küstermann, E., Arndt, S., Jacobs, A. H., Krone, W., Kahn, C. R., and Brüning, J. C. (2004). Role for neuronal insulin resistance in neurodegenerative diseases. Proc. Natl. Acad. Sci. U.S.A. 101, 3100-3105.

Serrano, J., Bevins, C. L., Young, S. W., and de Pablo, F. (1989). Insulin gene expression in chicken ontogeny: pancreatic, extrapancreatic, and prepancreatic. Dev. Biol. 132, 410-418.

Slaidina, M., Delanoue, R., Gronke, S. Partridge, L., and Léopold, P. (2009). A Drosophila insulin-like peptide promotes growth during nonfeeding states. Dev. Cell 17, 874-884.

Steen, E., Terry, B. M., Rivera, E. J., Cannon, J. L., Neely, T. R., Tavares, R., Xu, X. J., Wands, J. R., and de la Monte, S. M. (2005). Impaired insulin and insulin-like growth factor expression and signaling mechanisms in Alzheimer's disease - is this type 3 diabetes? J. Alzheimers Dis. 7, 63-80.

Steiner, D. F., Bell, G.I., and Tager, H. S. (1990). "Chemistry and biosynthesis of pancreatic protein hormones," in Endocrinology, ed. L. J. De Groot (Philadelphia: WB Saunders Co.), 1263-1289.

Taguchi, A., and White, M. F. (2008). Insulin-like signaling, nutrient homeostasis, and life span. Annu. Rev. Physiol. 70, 191-212.

Tong, M., Dong, M., and de la Monte, S. M. (2009). Brain insulin-like growth factor and neurotrophin resistance in Parkinson's disease and dementia with Lewy bodies: potential role of manganese neurotoxicity. $J$. Alzheimers Dis. 16, 585-599.

Torres-Aleman, I. (2010). Toward a comprehensive neurobiology of IGF-I. Dev. Neurobiol. 70, 384-396.

Valenciano, A. I., Corrochano, S., de Pablo, F., de la Villa, P., and de la
Rosa, E. J. (2006). Proinsulin/insulin is synthesized locally and prevents caspase- and cathepsin-mediated cell death in the embryonic mouse retina. J. Neurochem. 99, 524-536.

Wilkinson, T. N., and Bathgate, R. A. (2007). The evolution of the relaxin peptide family and their receptors. Adv. Exp. Med. Biol. 612, 1-13.

Yang, Y., Hua, Q. X., Liu, J., Shimizu, E. H., Choquette, M. H., Mackin, R. B., and Weiss, M. A. (2010). Solution structure of proinsulin: connecting domain flexibility and prohormone processing. J. Biol. Chem. 285, 7847-7851.

Zhao, W. Q., de Feliced, F. G., Fernández, S., Chen, H., Lambert, M. P., Quon, M. J., Krafft, G. A., and Klein, W. L. (2008). Amyloid beta oligomers induce impairment of neuronal insulin receptors. FASEB J. 22, 246-260.

Conflict of Interest Statement: The authors declare that part of the research was performed after they were founders and scientific advisors of the CIB-CSIC spin-off company ProRetina Therapeutics S. L.

Received: 13 July 2011; paper pending published: 09 August 2011; accepted: 22 August 2011; published online: 13 September 2011.

Citation: de la Rosa EJ and de Pablo F (2011) Proinsulin: from hormonal precursor to neuroprotective factor. Front. Mol. Neurosci. 4:20. doi: 10.3389/fnmol.2011.00020

Copyright (c) 2011 de la Rosa and de Pablo. This is an open-access article subject to a non-exclusive license between the authors and Frontiers Media SA, which permits use, distribution and reproduction in other forums, provided the original authors and source are credited and other Frontiers conditions are complied with. 